\title{
Modulation of Airway Inflammation in Cystic Fibrosis , \\ In Vivo Suppression of Interleukin-8 Levels on the Respiratory Epithelial Surface by Aerosolization of Recombinant Secretory Leukoprotease Inhibitor
}

\author{
N. G. McElvaney, ${ }^{*}$ H. Nakamura, ${ }^{*}$ P. Birrer, ${ }^{\star}$ C. A. Hébert, ${ }^{\star}$ W. L. Wong, ${ }^{\star}$ M. Alphonso, ${ }^{\star}$ \\ J. B. Baker, ${ }^{*}$ M. A. Catalano, and R. G. Crystal* \\ * Pulmonary Branch, National Heart, Lung, and Blood Institute, National Institutes of Health, Bethesda, Maryland 20892; \\ ${ }^{\ddagger}$ Genentech Inc., South San Francisco, California 94080; and ${ }^{\$}$ Synergen, Boulder, Colorado 80301
}

\begin{abstract}
Based on the knowledge that neutrophil elastase (NE) in cystic fibrosis (CF) epithelial lining fluid (ELF) can induce human bronchial epithelial cells to express the gene for interleukin 8 (IL-8), an 8.5-kD neutrophil chemoattractant, we have evaluated CF ELF for the presence of $\mathrm{IL}-8$, and investigated the ability of aerosolized recombinant secretory leukoprotease inhibitor (rSLPI) to suppress NE, and hence IL-8, levels on the respiratory epithelial surface in CF. Enzyme-linked immunoassay revealed 21.9 $\pm 4.8 \mathrm{nM}$ IL-8 in CF ELF compared with none in normals. Active NE was detectable in ELF of all individuals with $C F$ and was significantly decreased $(P<0.03)$ after aerosolization of rSLPI. Human bronchial epithelial cells exposed to CF ELF recovered before rSLPI therapy expressed IL-8 mRNA transcripts, but ELF recovered after rSLPI therapy induced far less bronchial epithelial cell IL-8 gene expression. Consistent with this, rSLPI aerosol therapy caused a marked reduction in CF ELF IL-8 levels $(P<0.05)$ and neutrophil number $(P<0.02)$. There was also a clear association between CF ELF active NE and IL-8 levels $(r=0.94)$. These data suggest that rSLPI therapy not only suppresses respiratory epithelial NE levels, but also breaks a cycle of inflammation on the CF epithelial surface. (J. Clin. Invest. 1992. 90:12961301.) Key words: aerosol therapy • antiprotease • cytokine • neutrophil chemoattractant • neutrophil elastase
\end{abstract}

\section{Introduction}

Cystic fibrosis (CF), ${ }^{1}$ a chronic disorder caused by mutations of the cystic fibrosis transmembrane conductance regulator (CFTR) gene, has its major clinical manifestations in the lung, with accumulation of purulent mucus, bacterial infections, and airway inflammation and obstruction leading to respiratory failure and death usually by the third decade $(1-4)$. The exact mechanisms by which mutations of the CFTR gene result in these respiratory manifestations are not clear, but it is recognized that epithelial inflammation dominated by neutrophils plays a major role in the respiratory derangements associated with this disease (4-6). Although the neutrophils that accumu-

Address reprint requests to Pulmonary Branch, Building 10, Room 6D03, National Institutes of Health, Bethesda, MD 20892.

Received for publication 1 October 1991 and in revised form 16 March 1992.

1. Abbreviations used in this paper: CF, cystic fibrosis; CFTR, cystic fibrosis transmembrane conductance regulator; ELF, epithelial lining fluid; NE, neutrophil elastase; SLPI, secretory leukoprotease inhibitor; rSLPI, recombinant SLPI.

The Journal of Clinical Investigation, Inc.

Volume 90, October 1992, 1296-1301 late on the airway epithelial surface may act appropriately and help in the clearance of microorganisms, they also have a deleterious effect on the epithelium itself (7-11). To a large extent, this damage is mediated by neutrophil elastase (NE), a proteolytic enzyme which directly damages epithelial cells, and interferes with normal host defense $(5,7,9-14)$. Although the lung normally has sufficient amounts of serine antiproteases on the epithelial surface to protect against NE, the burden of neutrophils and hence NE is so great in CF that the serine antiprotease defensive shield is overwhelmed $(5,6,15,16)$.

The mechanisms by which neutrophils are attracted to the epithelial surface in CF are complex, and likely involve a variety of neutrophil chemoattractants generated in the airways $(17,18)$. One neutrophil chemoattractant, interleukin 8 (IL8 ), may play a significant role in this process. IL-8, an $8.5-\mathrm{kD}$ protein with potent neutrophil chemoattractive and activating properties, can be produced by bronchial epithelial cells after exposure to a variety of inflammatory mediators (19-23). In the context of $\mathrm{CF}$, we have recently observed that respiratory epithelial lining fluid (ELF) of individuals with CF will induce cultured human bronchial cells to express the IL-8 gene and secrete IL-8, and that the mediator in CF ELF responsible for inducing IL-8 gene expression in the epithelial cells was NE (24). Further, the ability of CF ELF to induce bronchial cells to express the IL-8 gene could be suppressed in vitro with inhibitors of NE. Based on these observations, it is reasonable to postulate that in the CF lung, there is a cycle of respiratory inflammation in which neutrophils release large amounts of NE onto the respiratory epithelial surface which, in response, produces IL-8 with subsequent attraction of more neutrophils to that surface.

In the context that excessive amounts of neutrophils, and their product NE, play a major role in the pathogenesis of the respiratory manifestations of CF, and that free NE in CF ELF can induce bronchial epithelial IL-8 gene expression, the present study is directed toward evaluating this pathogenic scenario in vivo. In this regard, we have asked: $(a)$ is there evidence of increased amounts of IL-8 on the respiratory epithelial surface in CF; and $(b)$ if so, will in vivo suppression of the levels of active NE on the respiratory epithelial surface with a serine antiprotease suppress the ability of CF ELF to induce IL-8 gene expression in bronchial epithelial cells in vitro and suppress the levels of IL-8 on the respiratory epithelial surface in vivo?

\section{Methods}

Study population. The diagnosis of CF was made in 20 individuals ( 13 males, 7 females; aged $27 \pm 2 \mathrm{yr})^{2}$ using standard criteria, including a sweat chloride test (4). All were nonsmokers. Pulmonary function

2. All data are expressed as mean $\pm \mathbf{S E M}$; all statistical comparisons were done with the paired two-tailed Student's $t$ test. 
(25) tests showed (as percent predicted) forced expired volume in $1 \mathrm{~s}$ $\left(\mathrm{FEV}_{1}\right) 50 \pm 4$, forced vital capacity (FVC) $68 \pm 5, \mathrm{FEV}_{1} / \mathrm{FVC} 72 \pm 3$, and diffusing capacity $74 \pm 4$. Baseline bronchoalveolar lavage $(26,27)$ in the CF group revealed $134 \pm 18 \times 10^{3}$ total cells / $\mu$ l of ELF including $73 \pm 5 \%$ neutrophils, $26 \pm 5 \%$ macrophages, $<1 \%$ lymphocytes, and $<1 \%$ eosinophils.

To establish the status of IL-8 in normal ELF, 10 normals ( $29 \pm 2 \mathrm{yr}$; four males, six females, all nonsmokers) were evaluated. All had normal histories, physical examinations, chest roentgenograms, and lung function tests. Bronchoalveolar lavage in the normals revealed $30 \pm 3$ $\times 10^{3}$ total cells $/ \mu$ l of ELF, including $1 \pm 1 \%$ neutrophils, $93 \pm 1 \%$ alveolar macrophages, $4 \pm 1 \%$ lymphocytes and $<1 \%$ eosinophils.

$I L-8, N E$, and secretory leukoprotease inhibitor (SLPI) in ELF. ELF was recovered by bronchoalveolar lavage, as previously described (28). The presence and form of IL-8 in respiratory ELF was evaluated using Western analysis of 50-fold concentrated ELF (Centricon 3, Amicon Inc., Beverly, MA) with $15 \%$ sodium dodecyl sulphate (SDS) polyacrylamide gels and a polyclonal anti-human IL-8 antibody (Biosource International, Westlake Village, CA). Levels of IL-8 in ELF were quantified by an enzyme-linked immunoassay (ELISA) using a pair of monoclonal antibodies against IL-8 (Genentech, Inc., South San Francisco, CA). Samples were serially diluted and a mean value determined from four replicates. This monoclonal-based IL-8 ELISA is very sensitive (assay range $15-560 \mathrm{pM}$ ) and highly specific (no detectable cross-reactivity with recombinant human interleukin-1 (IL-1), IL-2, IL-4, IL-6, interferon- $\gamma$, tumor necrosis factor- $\alpha$, or granulocyte monocyte colony-stimulating factor). The amount of active NE in ELF was determined using the NE-specific substrate methoxy-succinyl-alanyl-alanyl-prolyl-valyl-nitroanilide in comparison to a NE standard of known activity (28). The levels of SLPI in ELF were quantified using a double-sandwich ELISA (29). The volume of ELF was measured by the urea method (27). NE activity, SLPI, and ELF measures were all performed in triplicate and the mean determined.

In vivo administration of recombinant SLPI (rSLPI). rSLPI (Synergen, Boulder, $\mathrm{CO}$ ) is a $12-\mathrm{kD}$ single-chain nonglycosylated protein identical in structure and function as an inhibitor of NE to normal human SLPI (30). rSLPI, produced in Escherichia coli transformed with an SLPI expression vector as previously described (31), retains its structure and function when aerosolized in vitro or to experimental animals (32).

Aerosolization of rSLPI to individuals with CF was carried out in two phases: an initial dose escalation study to evaluate safety and to provide an initial estimate of in vivo pharmacokinetics, followed by a 1 -wk study with a fixed dose for $7 \mathrm{~d}$. Two individuals participated in both phases with an interval of $>1$ mo between the two phases. The aerosol was generated with a compressed air-driven nebulizer (32). In vitro studies demonstrated the generated aerosol had a mass median diameter of $2.8 \mu \mathrm{m}$, similar to the characteristics of the aerosol used to deliver rSLPI to the respiratory epithelial surface of large animals (32). For the initial dose escalating study, five individuals with $\mathrm{CF}$ received rSLPI at an escalating once daily dose of $1,12.5,25,50$, and $100 \mathrm{mg}$, immediately followed by a twice daily dose of $100 \mathrm{mg}$ for $2 \mathrm{~d}$. All were evaluated by bronchoalveolar lavage before therapy and $12 \mathrm{~h}$ after the last aerosol. For the 1-wk study 17 individuals with CF received an aerosol of rSLPI at a dose of $100 \mathrm{mg}$ twice daily for $7 \mathrm{~d}$ and were evaluated by lavage pretherapy and at $4 \mathrm{~h}(n=8)$ or $12 \mathrm{~h}(n=8)$ after their 13 th and 14 th aerosol, respectively. One individual was removed from protocol because of inability to use the nebulizer device secondary to a preexisting debilitating extrapyramidal tremor; these results are not included.

IL-8 expression by bronchial epithelial cells. To evaluate the role of neutrophil elastase in CF ELF in inducing IL-8 gene expression in bronchial epithelium, the BET-1A human bronchial epithelial cell line (33) was exposed to ELF from individuals with CF. The cells were cultured in serum-free LHC-9 medium with $25 \mu \mathrm{g} / \mathrm{ml}$ fungizone, 25 $\mathrm{U} / \mathrm{ml}$ penicillin, and $25 \mu \mathrm{g} / \mathrm{ml}$ streptomycin (all from Biofluids Inc., Rockville, MD) (34). All studies were carried out when the cells were $70-80 \%$ confluent. To these cells were added: $10 \mathrm{nM}$ NE alone, $10 \mathrm{nM}$
NE plus $500 \mathrm{nM}$ rSLPI, $1 \mu \mathrm{lELF}$ (per milliliter of media) from normal individuals, $1 \mu \mathrm{l} \mathrm{ELF}$ (per milliliter of media) from CF patients pretherapy, $1 \mu$ l ELF (per milliliter of media) from the same CF patients pretherapy with $500 \mathrm{nM}$ rSLPI added in vitro and $1 \mu \mathrm{l} \mathrm{ELF} \mathrm{(per} \mathrm{milli-}$ liter media) from the same CF patients after in vivo rSLPI aerosol therapy. After incubation $\left(3 \mathrm{~h}, 37^{\circ}\right)$, IL-8 mRNA transcripts were evaluated in the BET-1A cells by Northern analysis (35). Total cellular RNA was isolated by the guanidium thiocyanate-CsCl gradient method (36). The RNA ( $10 \mu \mathrm{g}$ per lane) was evaluated by formaldehyde-agarose gel electrophoresis, transfer to nylon membranes (Nytran; Schleicher \& Schuell, Inc., Keene, NH), and hybridization with a ${ }^{32} \mathrm{P}$ labeled IL-8 (pPB 248) or, as a control, $\beta$-actin cDNA (pHF $\beta$ A-1) probe generated by the random priming method, and autoradiography $(23,37,38)$. The IL-8 cDNA probe was constructed using polymerase chain reaction amplification of RNA (after conversion to cDNA) from lipopolysaccharide-stimulated human blood monocytes (23).

\section{Results}

Although IL-8 was undetectable in ELF from normal individuals, it was clearly present in ELF of individuals with CF (Fig. 1). Western analysis demonstrated no IL-8 in ELF of normals, but the 8.5-kD IL-8 molecule was detectable in CF ELF (Fig. 1 $A$ ). The ELISA for IL-8 sufficiently sensitive to detect as little as 15 pM IL-8 did not detect IL-8 in normal ELF. However, in ELF from CF individuals, high levels of IL-8 are detected ranging from 1.7 to $98.1 \mathrm{nM}$, with an average of $21.9 \pm 4.8 \mathrm{nM}$ (Fig. $1 B$ ). As previously observed (29), SLPI was present in ELF of individuals with CF (range $0.02-4.80 \mu \mathrm{M}$, Fig. $2 A$ ), as was active NE (range 1.2-85.7 $\mu \mathrm{M}$, Fig. $2 B$ ) i.e., despite the presence of SLPI, the burden of NE is so great in CF ELF that it far overweighs the anti-NE defenses, permitting active NE to be present in ELF.

Aerosol therapy with rSLPI was well tolerated, patients taking $\sim 25 \mathrm{~min}$ to inhale a complete $100-\mathrm{mg}$ dose of rSLPI. The initial study with an escalating dose of rSLPI suggested that a dose of $100 \mathrm{mg}$ every $12 \mathrm{~h}$ would significantly raise ELF SLPI levels and suppress ELF active NE levels. After aerosolization of rSLPI, ELF levels of SLPI increased significantly, compared to pretherapy levels $(P<0.01)$ (Fig. $2 A)$. Western blot analysis of ELF pretherapy showed SLPI in a cleaved or complexed form, but after aerosolization of rSLPI, normal molecular size SLPI was now evident in ELF (not shown). The augmentation

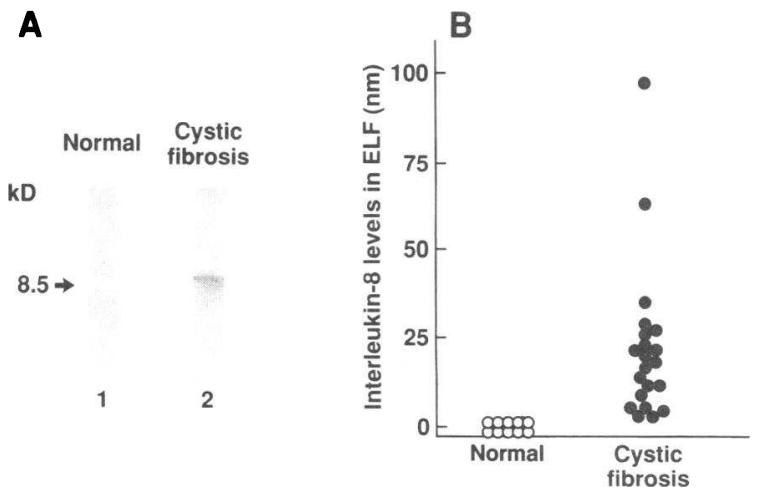

Figure 1. Form and levels of IL-8 in respiratory ELF. $(A)$ Western analysis in respiratory ELF for the presence of IL-8. Lane 1, normal individual; lane 2 , individual with cystic fibrosis (CF). The migration of an 8.5-kD IL-8 standard is indicated. $(B)$ Levels of IL-8 in respiratory ELF from normals and individuals with CF. Each data point represents the average of four determinations for each individual. 

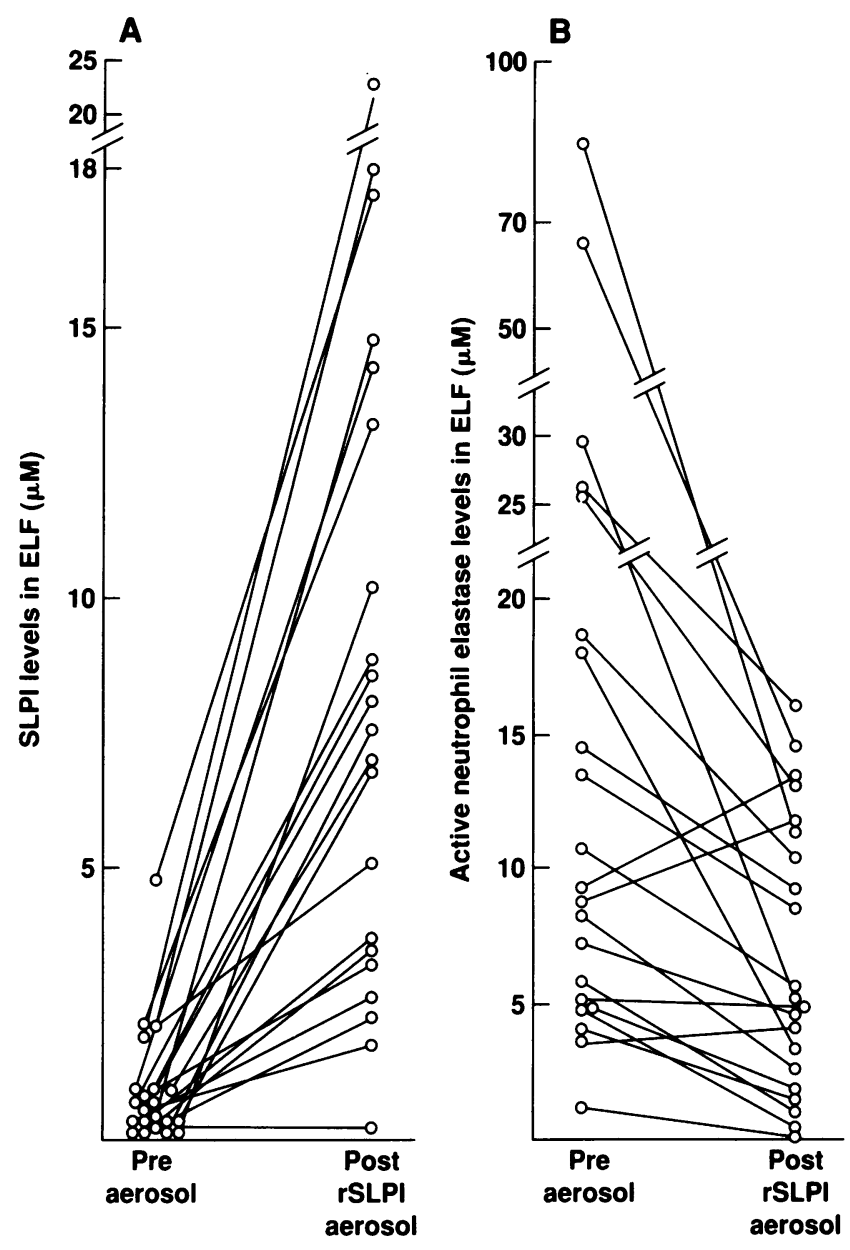

Figure 2. Effect of rSLPI aerosol therapy on SLPI and active NE levels in ELF of individuals with CF. $(A)$ SLPI levels in CF ELF before and after rSLPI aerosol therapy. (B) NE levels in CF ELF before and after rSLPI aerosol therapy. Each datapoint represents the average of three determinations for each individual.

in ELF SLPI levels was associated with a concomitant fall in ELF active NE levels in almost all individuals (Fig. $2 B$ ). In this regard, for 18 of 21 individuals, there was a significant suppression of ELF NE. For the entire group, the pretherapy active NE levels decreased an average of $68 \%(P<0.03)$.

In the context that $\mathrm{NE}$ was present on the $\mathrm{CF}$ respiratory epithelial surface, and that NE in CF ELF is capable of inducing bronchial epithelial cells to express the IL-8 gene (24), CF ELF was assessed in vitro for its effect on IL-8 gene expression in bronchial epithelial cells before and after the individuals with CF received aerosol therapy with rSLPI. Resting BET-1A cells demonstrated no detectable IL-8 mRNA transcripts (Fig. 3 , lane 1), but after exposure to active NE, 1.8-kb IL-8 gene transcripts were present (lane 2). The IL-8 gene expression by NE was obviated by the addition of rSLPI in vitro (lane 3). ELF from normal individuals added to BET-1A cells did not induce IL-8 gene expression (lane 4). However, ELF from CF individuals caused a marked expression of the IL-8 gene as evidenced by easily detectable IL-8 mRNA transcripts (lane 5 ), which was prevented by the in vitro addition of rSLPI to the CF ELF (lane 6). Strikingly, in contrast to CF ELF pretherapy (lane 5), ELF from CF patients post-rSLPI aerosol therapy caused markedly decreased IL-8 gene expression in bronchial epithelial cells (lane 7).

Consistent with these in vitro studies, levels of IL-8 in CF ELF fell dramatically with rSLPI therapy (Fig. 4). In this regard, for 15 of $21 \mathrm{CF}$ individuals receiving the rSLPI aerosol, ELF IL-8 levels decreased; for the group as a whole there was a $50 \%$ reduction in ELF IL-8 levels (before therapy $21.7 \pm 4.8$ $\mathrm{nM}$, after therapy $10.7 \pm 1.4 \mathrm{nM} ; P<0.05)$. Concomitant with this was a fall in the number of neutrophils in ELF (Fig. 5; before therapy $10.6 \pm 1.8 \times 10^{4} / \mu \mathrm{L}$ of ELF, after therapy $5.8 \pm 0.8 \times 10^{4} / \mu \mathrm{L}$ of ELF; $\left.P<0.02\right)$. Further, as evidence that NE in CF ELF induced IL-8 gene expression in vivo, the relationship of ELF IL-8 and active NE in CF ELF (all data combined, including before and after therapy) demonstrated a remarkable correlation $(r=0.94, P<0.01$; Fig. 6$)$.

\section{Discussion}

IL-8, an $8.5-\mathrm{kD}$ potent chemoattractant and activator of neutrophils, is released by bronchial epithelial cells in response to a variety of inflammatory stimuli, including NE (19-24). The present study demonstrates that IL-8 is not detectable in normal respiratory epithelial lining fluid, but is present in large quantities in CF ELF, a disorder characterized by neutrophildominated chronic respiratory tract inflammation (4-6). In vitro studies have demonstrated that NE will induce bronchial epithelial cells to express the IL-8 gene and release IL-8, and that the active NE in respiratory ELF of individuals with CF has the same effect (24). The induction of the expression of the IL-8 gene is blocked by the addition of inhibitors of NE such as phenylmethylsulfonyl-fluoride, methoxy-succinyl-alanylalanyl-prolyl-valyl-chloromethyl ketone, plasma purified $\alpha_{1-}$ antitrypsin, or rSLPI. We therefore hypothesized that suppression of $\mathrm{NE}$ in vivo on the respiratory epithelial surface in $\mathrm{CF}$ would prevent respiratory epithelial cell IL-8 gene expression, consequently lowering CF ELF IL-8 levels and thereby decrease the neutrophil-dominated inflammation on the respiratory epithelial surface in CF. This is what was observed. When rSLPI was aerosolized to individuals with CF, respiratory ELF

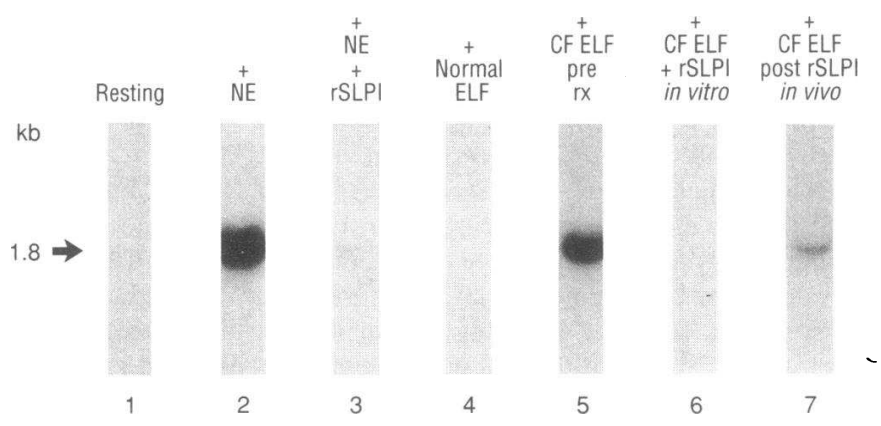

Figure 3. Northern analysis of IL-8 mRNA transcripts in BET-1A bronchial epithelial cells. All lanes contained $10 \mu \mathrm{g}$ of total cellular RNA. Lane 1, cells at rest; lane 2, cells exposed to NE; lane 3, cells exposed to NE + rSLPI; lane 4, cells exposed to ELF from a normal individual; lane 5, cells exposed to ELF from as individual with CF before rSLPI aerosol therapy; lane 6 , as in lane 5 , but with rSLPI added in vitro; and lane 7, ELF from the same individual as lanes 5 and 6 , but after in vivo rSLPI aerosol administration. The $1.8-\mathrm{kb}$ IL-8 mRNA transcripts are indicated. Parallel analysis with a $\gamma$-actin probe showed $\gamma$-actin transcripts of equal intensity in all lanes (not shown). 


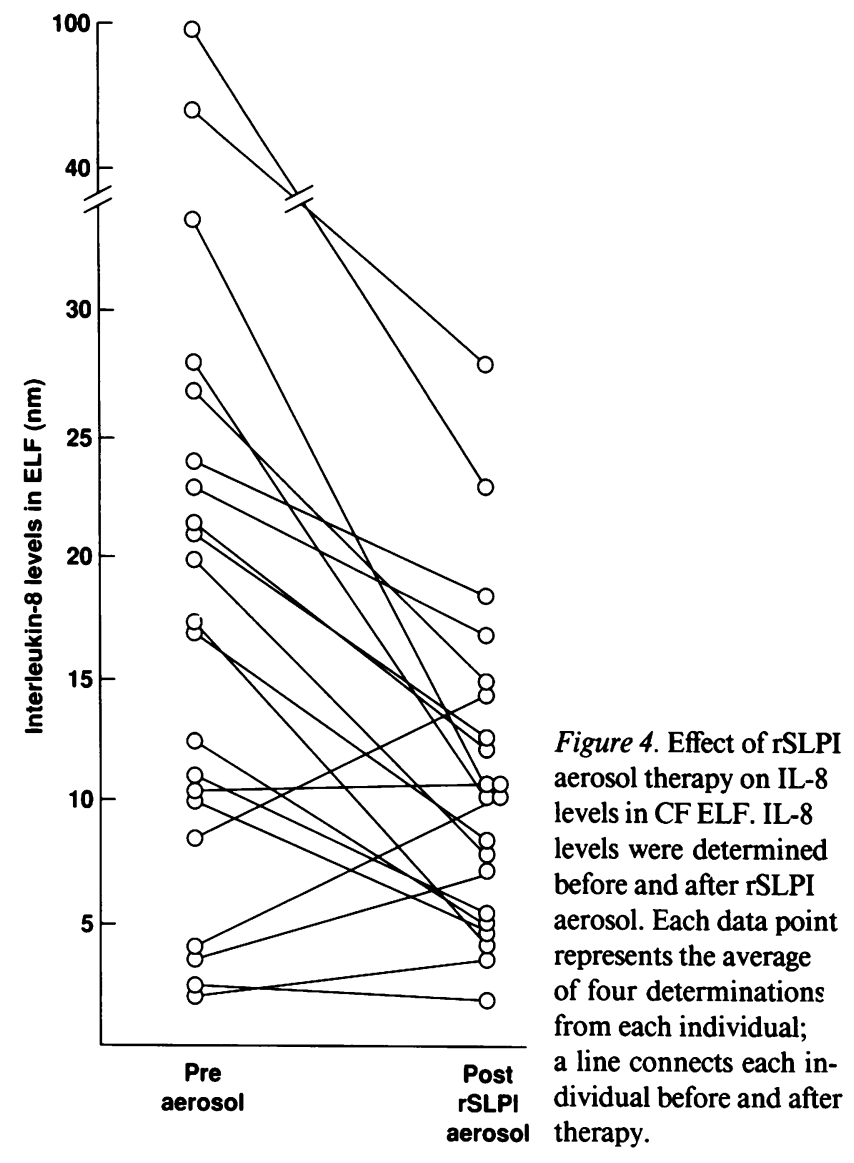

SLPI levels increased, ELF active NE levels decreased, CF ELF had markedly diminished ability to induce IL- 8 gene expression in bronchial epithelial cells in vitro, ELF IL-8 levels were markedly suppressed in vivo, and the number of neutrophils in ELF decreased. Although it is not possible to examine the bronchial epithelium per se for IL-8 gene expression in vivo, the fact that there was an excellent correlation between CF ELF IL-8 and active NE levels strongly supports the link between NE and respiratory epithelial cell IL-8 gene expression observed in vitro.

The major clinical manifestations of $\mathrm{CF}$ take place on the respiratory epithelial surface (4-6). Although neutrophils in the lung in $\mathrm{CF}$ must have a protective value in regards to host defense, the massive chronic neutrophil-dominated inflammatory response in $\mathrm{CF}$ is associated with chronic epithelial damage (4-11). There is growing evidence that NE released by the neutrophils plays a major role in this process, not only by its direct assault on the respiratory epithelial surface but also by impairing lung defense by virtue of its ability to adversely affect mucociliary clearance, and to cleave immunoglobulins, complement components, and complement receptors on neutrophils $(9-14,39)$. The later observation is of particular importance for respiratory host defense, in that many of the neutrophils attracted to the CF lung may be rendered ineffective and thus may cause damage rather than provide antimicrobial protection $(5,12,13)$. The fact that NE can act as an abnormal stimulus to IL-8 production on the bronchial epithelial surface suggests it plays a central role in a cycle of inflammation, stimulating IL-8 release leading to more neutrophil accumulation with more NE release. Furthermore, IL-8 promotes NE release from neutrophils, thereby accentuating this cycle of inflammation (40). In addition to bronchial epithelial cells, other cells in the CF lung may contribute to the IL- 8 burden on the respiratory epithelial surface, including macrophages, neutrophils, alveolar epithelial cells, endothelial cells, and fibroblasts (1924). It is difficult to assess the role of NE in inducing IL-8 gene expression for most of these cells in vivo because of their inaccessability (alveolar epithelium, endothelium, and fibroblasts) or chronic stimulation secondary to bacteria (macrophages and neutrophils), and thus, for now their relative contribution to NE induced IL-8 expression compared to that of the bronchial epithelium in CF lung is unknown. However, the clear effect of NE on bronchial cells, taken in conjunction with the in vivo relationships between active NE and IL-8 in CF ELF, suggest the bronchial epithelium as a significant contributor to NE-induced IL-8 production in the CF lung.

The major protection of the lung against NE includes $\alpha_{1}$ antitrypsin and SLPI. $\alpha_{1}$-Antitrypsin, a $52-\mathrm{kD}$ glycoprotein, is produced in the liver and secreted into plasma where it is available to diffuse across into tissues including the lung (15). SLPI, a $12-\mathrm{kD}$, nonglycosylated, disulfide-linked antiprotease secreted by cells of mucosal surfaces including the epithelium of the airways, provides the major anti-NE protection of the large airways $(15,29,41-43)$. In CF, the endogenous anti-NE defenses are overwhelmed and inactivated due to the massively increased burden of NE. This is true for both $\alpha_{1}$-antitrypsin and SLPI; both molecules in CF ELF are complexed with NE, proteolytically cleaved, or modified by oxidants released by inflammatory cells $(5,16,29)$. Thus, in CF there is a major imbalance on the epithelial surface between the large burden of $\mathrm{NE}$ and the ineffective anti-NE defenses. This imbalance can be redressed and the active NE on the epithelial surface suppressed by aerosol augmentation with recombinant SLPI. rSLPI can be placed in aerosol droplets capable of depositing on the respiratory epithelial surface without losing form or function. The molecule is acid stable and thus may retain function in the environment of the neutrophil metabolic burst (44, 45 ). Further, rSLPI has an isoelectric point similar to that of

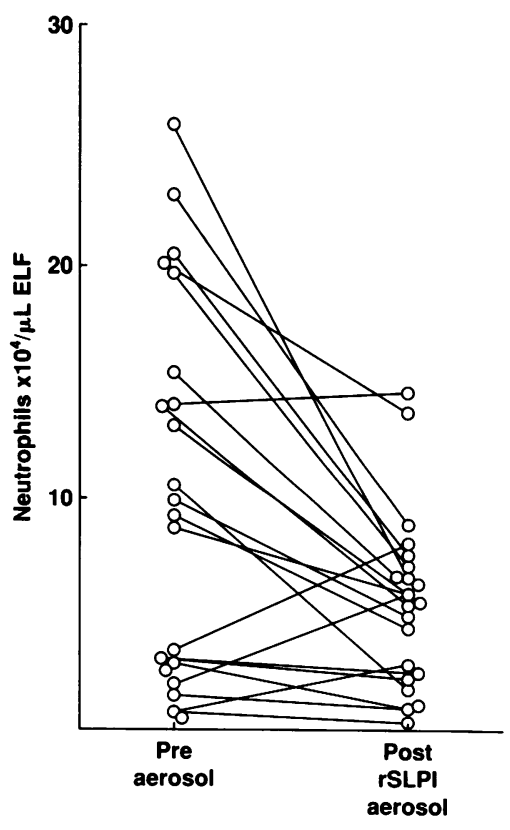

Figure 5. Effect of rSLPI aerosol therapy on the number of neutrophils in CF ELF. Neutrophil numbers were determined before and after rSLPI aerosol. Each data point represents the average of two determinations for each individual. 


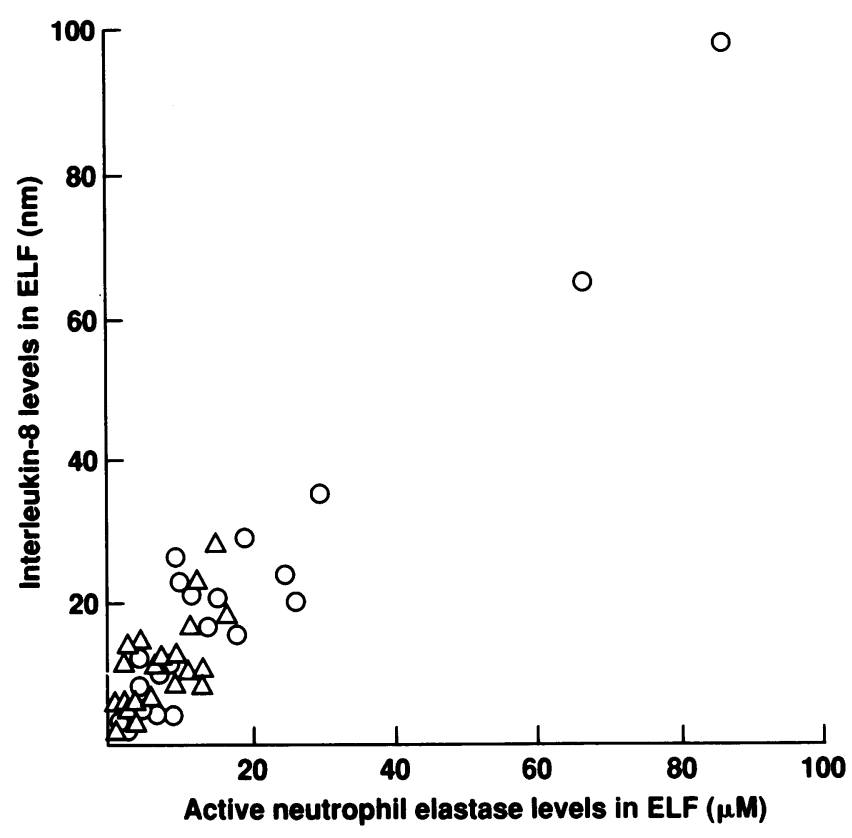

Figure 6. Correlation between IL-8 levels and active NE levels in ELF of individuals with CF. Included are data before therapy $(0)$ and after therapy $(\Delta)$. The data are based on Figs. $2 B$ and 4.

NE, and thus may be able to track NE to various tissue sites and inhibit tissue-bound NE $(15,29,45)$. Finally, whereas $\alpha_{1}$-antitrypsin provides $>90 \%$ of the anti-NE defenses of the lower respiratory tract, SLPI is the major anti-NE inhibitor of the bronchi $(15,29)$, and may be an ideal molecule for protecting the bronchial epithelium in disorders such as CF which are characterized by bronchial epithelial damage.

Aerosolization of rSLPI to individuals with CF suppresses the NE burden on the respiratory epithelial surface and at the same time greatly reduces the IL-8 levels in ELF. Although this may have little effect on other potential IL-8-inducing molecules such as tumor necrosis factor- $\alpha(23)$, the effect of rSLPI in inhibiting NE is of particular importance in CF because the massive NE burden on the epithelial surface is the most likely major local stimulus to IL-8 production $(5,24)$. The mechanisms by which NE induces IL-8 gene expression and IL-8 release from bronchial epithelium are unknown, but in vitro, NE induces bronchial epithelial cell IL-8 gene transcription, leading to increased IL-8 mRNA levels and secretion of functional IL-8 (24). Although there are many potential neutrophil chemoattractants in CF ELF other than IL-8, the fact that IL-8 mRNA transcript levels in bronchial epithelium can be markedly reduced in vitro and IL-8 protein levels in ELF markedly reduced in vivo by rSLPI administration, and the clear correlation between active NE levels and IL-8 levels in ELF before and after therapy, argue strongly for the role of NE as a major inducer of IL-8 in the CF lung. Furthermore, after aerosolization of rSLPI and the subsequent decrease in active NE and IL-8 levels in CF ELF, there was also a decrease in the number of neutrophils in ELF, further evidence for the role of IL-8 as a major neutrophil chemoattractant in this disorder. In this regard, suppression of the NE burden on the respiratory epithelial surface may remove the NE stimulus to local respiratory IL-8 production with resultant decrease in neutrophil chemoattraction in the lung, leading to less neutrophil chemoat- traction, less NE release, and thus decreased epithelial damage and reduced impairment of lung host defense in CF.

\section{References}

1. Rommens, J. M., M. C. Iannuzzi, B.-S. Kerem, M. L. Drumm, G. Melmer, M. Dean, R. Rozmahel, J. L. Cole, D. Kennedy, N. Hidaka, et al. 1989. Identification of the cystic fibrosis gene: chromosome walking and jumping. Science (Wash. DC). 245:1059-1065.

2. Riordan, J. R., J. M. Rommens, B.-S. Kerem, N. Alon, R. Rozmahel, Z. Grzelczak, J. Zielenski, S. Lok, N. Plavsic, J.-L. Chou, et al. 1989. Identification of the cystic fibrosis gene: cloning and characterization of complementary DNA. Science (Wash. DC). 245:1066-1073.

3. Kerem, B.-S., J. M. Rommens, J. A. Buchanan, D. Markiewicz, T. K. Cox, A. Chakravarti, M. Buchwald, and L.-C. Tsui. 1989. Identification of the cystic fibrosis gene: genetic analysis. Science (Wash. DC). 245:1073-1080.

4. Boat, T. F., M. J. Welsh, A. L. Beaudet. 1989. Cystic fibrosis. In The Metabolic Basis of Inherited Disease. C. R. Scriver, A. L. Beaudet, W. S. Sly, and D. Valle, editors. McGraw-Hill, Inc., New York, 2649-2680.

5. McElvaney, N. G., R. C. Hubbard, P. Birrer, M. S. Chernick, D. B. Caplan, M. M. Frank, and R. G. Crystal. 1991. Aerosol administration of $\alpha 1$-antitrypsin to suppress the burden of active neutrophil elastase on the respiratory epithelial surface in cystic fibrosis. Lancet. 337:392-394.

6. Suter, S. 1989. The imbalance between granulocyte neutral proteases and antiproteases in bronchial secretions from patients with cystic fibrosis. In Pseudomonas aeruginosa Infection. Antibiot. Chemother. (Basel). 42:158-168.

7. Hubbard, R., M. Brantly, and R. G. Crystal. 1991. Proteases. In The Lung. Sci. Found. 2:1763-1774.

8. Parsons, P. E., G. S. Worthen, and P. E. Henson. 1991. Injury from inflammatory cells. In The Lung. Sci. Found. 2:1981-1992.

9. Breuer, R., T. G. Christensen, R. M. Niles, P. J. Stone, and G. L. Snider. 1989. Human neutrophil elastase causes glycoconjugate release from the epithelial cell surfaces of hamster trachea in organ culture. Am. Rev. Respir. Dis. 139:779-782.

10. Lucy, E. C., P. J. Stone, T. G. Christensen, R. Breuer, and G. L. Snider. 1988. An 18-month study of the effects on hamster lungs of intratracheally administered human neutrophil elastase. Exp. Lung. Res. 14:671-686.

11. Lucey, E. C., P. J. Stone, and G. L. Snider. 1991. Consequences of proteolytic injury. In The Lung. Sci. Found. 2:1789-1801.

12. Berger, M., R. U. Soerensen, M. F. Tosi, D. G. Dearborn, and G. Döring. 1989. Complement receptor expression on neutrophils at an inflammatory site, the pseudomonas-infected lung in cystic fibrosis. J. Clin. Invest. 84:1302-1313.

13. Tosi, M. F., H. Zakem, and M. Berger. 1990. Neutrophil elastase cleaves C3bi on opsonized pseudomonas as well as CR1 on neutrophils to create a functionally important opsonin receptor mismatch. J. Clin. Invest. 86:300-308.

14. Fick, R. B., G. P. Naegel, S. Squier, R. E. Wood, J. B. L. Gee, and H. Y. Reynolds. 1984. Proteins of the cystic fibrosis respiratory tract: fragmented immunoglobulin $\mathrm{G}$ opsonic antibody causing defective opsonophagocytosis. J. Clin. Invest. 74:236-248.

15. Hubbard, R. C., and R. G. Crystal. 1991. Antiproteases. In The Lung. Sci. Found. 2:1775-1787.

16. Goldstein, W., and G. Døring. 1986. Lysosomal enzymes from polymorphonuclear leukocytes and proteinase inhibitors in patients with cystic fibrosis. Am. Rev. Respir. Dis. 134:49-56.

17. Sibille, Y., and H. Y. Reynolds. 1990. Macrophages and polymorphonuclear neutrophils in lung defense and injury. Am. Rev. Respir. Dis. 141:471-501.

18. Abramson, S. I., H. L. Malech, and J. I. Gallin. 1991. Neutrophils. In The Lung. Sci. Found. 1:553-563.

19. Leonard, E. J., and T. Yoshimura. 1990. Neutrophil attractant/activation protein-1 (NAP-1 [interleukin-8]). Am. J. Respir. Cell. Mol. Biol. 2:479-486.

20. Matsushima, K., and J. J. Oppenheim. 1989. Interleukin 8 and MCAF: novel inflammatory cytokines inducible by IL-1 and TNF. Cytokine. 1:2-13.

21. Baggiolini, M., A. Walz, and S. L. Kunkel. 1989. Neutrophil-activating peptide-1 / interleukin 8, a novel cytokine that activates neutrophils. J. Clin. Invest. 84:1045-1049.

22. Standiford, T. J., S. L. Kunkel, M. A. Basha, S. W. Chensue, J. P. Lynch III, G. B. Toews, J. Westwick, and R. M. Strieter. 1990. Interleukin-8 gene expression by pulmonary epithelial cell line: model for cytokine network in the lung. $J$. Clin. Invest. 86:1945-1953.

23. Nakamura, H., K. Yoshimura, H. A. Jaffe, and R. G. Crystal. 1991. Interleukin-8 gene expression in human bronchial epithelial cells. J. Biol. Chem. 266:19611-19617.

24. Nakamura, H., K. Yoshimura, N. G. McElvaney, and R. G. Crystal. 1992. Neutrophil elastase in respiratory epithelial lining fluid of individuals with cystic fibrosis induces interleukin-8 gene expression in a human bronchial epithelial cell line. J. Clin. Invest. 89:1478-1484.

25. Fulmer, J. D., W. C. Roberts, E. R. von Gal, and R. G. Crystal. 1977. 
Small airways in idiopathic pulmonary fibrosis: Comparison of morphologic and physiologic observations. J. Clin. Invest. 60:595-610.

26. Saltini, C., A. J. Hance, V. J. Ferrans, F. Basset, P. B. Bitterman, and R. G. Crystal. 1984. Accurate quantification of cells recovered by bronchoalveolar lavage. Am. Rev. Respir. Dis. 130:650-658.

27. Rennard, S. I., G. Basset, D. Lecossier, K. M. O'Donnell, P. Pinkston, P. G. Martin, and R. G. Crystal. 1986. Estimation of volume of epithelial lining fluid recovered by lavage using urea as marker of dilution. J. Appl. Physiol. 60:532-538.

28. Wewers, M. D., M. A. Casolaro, S. E. Sellers, S. C. Swayze, K. M McPhaul, J. T. Wittes, and R. G. Crystal. 1987. Replacement therapy for alpha $a_{1}$ antitrypsin deficiency associated with emphysema. N. Engl. J. Med. 316:1055-1062.

29. Vogelmeier, C., R. C. Hubbard, G. A. Fells, H.-P. Schnebli, R. C. Thompson, H. Fritz, and R. G. Crystal. 1991. Anti-neutrophil elastase defense of the normal human respiratory epithelial surface provided by the secretory leukoprotease inhibitor. J. Clin. Invest. 87:442-448.

30. Thompson, R. C., and K. Ohlsson. 1986. Isolation, properties, and complete amino acid sequence of human secretory leukocyte protease inhibitor, a potent inhibitor of leukocyte elastase. Proc. Natl. Acad. Sci. USA. 83:6692-6696.

31. Miller, K. W., R. J. Evans, S. P. Eisenberg, and R. C. Thompson. 1989. Secretory leukocyte protease inhibitor binding to mRNA and DNA as a possible cause of toxicity to Escherichia coli. J. Bacteriol. 171:2166-2172.

32. Vogelmeier, C., R. Buhl, R. F. Hoyt, E. Wilson, G. A. Fells, R. C. Hubbard, H.-P. Schnebli, R. C. Thompson, and R. G. Crystal. 1990. Aerosolisation of recombinant secretory leukoprotease inhibitor as a strategy to augment the antineutrophil elastase protective screen of the pulmonary epithelial surface. J. Appl. Physiol. 69:1843-1848.

33. Reddel, R. R., Y. Ke, B. I. Gerwin, M. G. McMenamin, J. F. Lechner, R. T. Su, D. E. Brash, J.-B. Park, J. S. Rhim, and C. C. Harris. 1988. Transformation of humanbronchial epithelial cells by infection with SV40 or adenovirus-12 SV40 hybrid virus, or transfection via strontium phosphate coprecipitation with a plasmid containing SV40 early region genes. Cancer Res. 48:1904-1909.

34. Lechner, J. F., and M. A. LaVeck. 1985. A serum-free method for culturing normal human bronchial epithelial cells at clonal density. J. Tissue Culture Methods. 9:43-48.

35. Ausubel, F. M., R. Brent, R. E. Kingston, O. D. Moore, J. A. Smith, J. G.
Seidman, and K. Struhl. 1987. Analysis of RNA by Northern hybridization. In Current Protocols in Molecular Biology. John Wiley \& Sons, Inc., New York. 4.9.1.-4.9.8.

36. Chirgwin, J. M., A. E. Przybyla, R. J. MacDonald, and W. J. Rutter. 1978. Isolation of biologically active ribonucleic acid from sources enriched in ribonuclease. Biochemistry. 18:5294-5299.

37. Feinberg, A. P., and B. Vogelstein. 1983. A technique for radiolabeling DNA restriction endonuclease fragments to high specific activity. Anal. Biochem. 132:6-13.

38. Gunning, P., P. Ponte, H. Okayama, J. Engel, H. Blau, and L. Kedes. 1983. Isolation and characterization of full-length $\mathrm{CDNA}$ clones for human $\alpha-, \beta-$, and $\gamma$-actin mRNAs: Skeletal but not cytoplasmic actins have an amino-terminal cysteine that is subsequently removed. Mol. Cell. Biol. 3:787-795.

39. Sykes, B. A., R. Wilson, M. Greenstone, D. C. Currie, C. Steinfort, and P. J. Cole. Deleterious effects of purulent sputum sol on human ciliary function in vitro: at least two factors identified. Thorax. 42:256-261.

40. Hébert, C. A., F. W. Luscinskas, J.-M. Kiely, E. A. Luis, W. C. Darbonne, G. L. Bennett, C. C. Liu, M. S. Obin, M. A. Gimbrone, Jr., and J. B. Baker. 1990 Endothelial and leukocyte forms of IL-8. Conversion by thrombin and interactions with neutrophils. J. Immunol. 145:3033-3040.

41. Boudier, C., A. Pelletier, A. Gast, J.-M. Tournier, G. Pauli, and J. G. Bieth. 1987. The elastase inhibitory capacity and the $\alpha_{1}$-proteinase inhibitor and bronchial inhibitor content of bronchoalveolar lavage fluids from healthy subjects. Biol. Chem. Hoppe-Seyler. 368:981-90.

42. Kramps, J. A., C. Franken, and J. H. Dijkman. 1988. Quantity of antileucoprotease relative to $\alpha_{1}$-proteinase inhibitor in peripheral air spaces of the human lung. Clin. Sci. 75:351-353.

43. Morrison, H. M., J. A. Kramps, J. H. Dijkman, R. A. Stockley. 1986 Comparison of concentrations of two proteinase inhibitors, porcine pancreatic elastase inhibitory capacity, and cell profiles in sequential bronchoalveolar lavage samples. Thorax. 41:435-441.

44. Hochstraßer, K., R. Reichert, S. Schwarz, and E. Werle. 1972. Isolierung und Charakterisierung eines Proteaseninhibitors ausmenschlichem Bronchialsekret. Hoppe-Seyler's Z. Physiol. Chem. 353:221-226.

45. Rice, W. G. and S. J. Weiss. 1990. Regulation of proteolysis at the neutrophil-substrate interface by secretory leukoprotease inhibitor. Science (Wash DC). 249:178-181. 